\title{
Un manuscrito póstumo e inédito de 200 años: Cuaderno de viajes y observaciones de Francisco José de Caldas entre 1802 y 1807
}

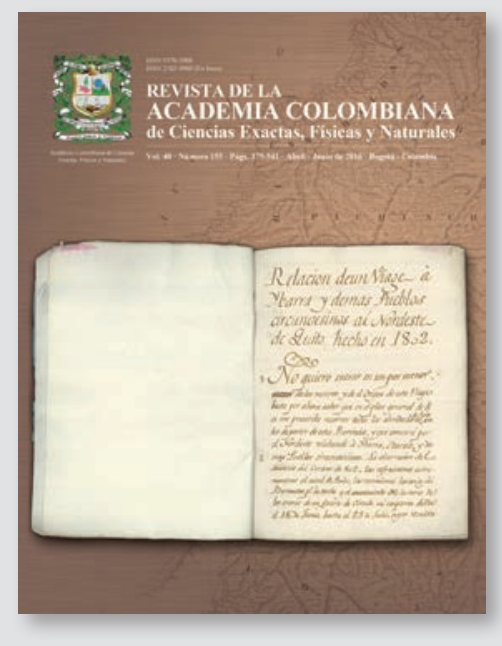

Francisco José de Caldas nació en Popayán a comienzos del mes de octubre de 1768 y murió en Bogotá 48 años después, en 1816, a finales del mismo mes de octubre.

Doscientos años después de su muerte, la Pontificia Universidad Javeriana pudo recuperar en Francia uno de sus cuadernos manuscritos, con doce estudios de viaje y observaciones científicas que abarcan los siguientes temas y folios:

1- Relacion de un Viage à Ybarra y demas Pueblos circunvesinos al Nordeste de Quito hecho en 1802 (28)

2- Aves (35)

3- Quito (8)

4- Descripción casa Marqués de Selva alegre en Chillo (3)

5- Huerto y jardín de Chillo (1)

6- Viage a las pirámides y base de Yaruqui (15)

7- Viage a Pitchincha (28)

8- Viage al Panecillo (4)

9- Materiales para la Memoria sobre los árboles de Quina (1)

10- Determinación del término de la nieve perpetua en las cercanías del ecuador (5)

11- Determinación del término de la vegetación en las cercanías del ecuador (Trigo, Cinchona, Spondias, Tabaco, Coccos butyracea, Bambusa exandra, Caucho (Ficus), Heliconia, Canelo(Laurus cinamomoides), Grandes cocos de Cali (Coccos nucifera), Chuquiraga, Musa (Plátano), Theobroma cacao (13)

12- Trabajos geodésicos sobre Ymbabura (4)

Los contenidos de estos doce estudios están registrados en 118 folios manuscritos, además de 76 folios en blanco que los separan en un volumen encuadernado en 1802 .

La amplitud temática que revelan estos títulos se amplía considerablemente al seguir folio tras folio su contenido, muy rico en conceptos y mediciones originales. El análisis detallado de cada uno de ellos revela nuevas apreciaciones de Caldas sobre su entorno en la primera década del siglo XIX, y permite fundamentar nuevas hipótesis sobre el alcance de sus trabajos a partir de su vinculación a la Expedición Botánica a mediados de ese mismo año de 1802, cuando aún vivía en los territorios que hoy hacen parte del Ecuador.

Estos trabajos son particularmente significativos en lo que se refiere a la geografía de las plantas, materia que se ha asociado usualmente al nombre de Alexander von Humboldt, pero que, gracias al detalle de las observaciones de este diario, puede asociarse también a Francisco José de Caldas como su gestor simultáneo.

La primera noticia de este cuaderno manuscrito se encuentra en el inventario de la biblioteca de Caldas elaborado en mayo 22 de 1816, algo más de cinco meses antes de su fusilamiento en Bogotá. La segunda mención se halla en el avalúo "de lo que quedaba de esta biblioteca" el 18 de junio, menos de un mes después, cuando Caldas se registró como "emigrado", dos semanas antes de ser apresado en su hacienda de Paispamba, al sur de Colombia. 
Los 12 estudios de este manuscrito inédito hacen parte de una serie total de 44 textos caldasianos fechados entre 1795 y 1808 que se han podido registrar hasta hoy, es decir que configuran cerca de la tercera parte de sus estudios antes de iniciar la publicación del Semanario del Nuevo Reyno de Granada, antes del fallecimiento de José Celestino Mutis, quien se convirtió en su protector a partir de 1802, y antes de cumplir 40 años.

Un buen complemento de estos 44 textos, varios de ellos aún inéditos, son las 32 cartas que Caldas escribió a Mutis en el curso de su vida, las cuales fueron editadas en 1978 en la Academia Colombiana de Ciencias Exactas, Físicas y Naturales, gracias a la coordinación de Alfredo Bateman y de Jorge Arias de Greiff.

La Pontificia Universidad Javeriana pondrá este manuscrito inédito a disposición del público general y de los académicos interesados en el 2017, una vez haya sido debidamente digitalizado y analizado en profundidad por un número plural de profesores.

\section{Alberto Gómez Gutiérrez, PhD FLS}

Director Instituto de Genética Humana

Facultad de Medicina

Pontificia Universidad Javeriana 